\title{
ORGANOGÊNESE DIRETA EM EXPLANTES CAULINARES DE MANGABEIRA (Hancornia speciosa Gomes)
}

\author{
Direct organogenesis in nodal explants of mangabeira (Hancornia speciosa Gomes)
}

\author{
Fernanda Pereira Soares ${ }^{1}$, Renato Paiva ${ }^{2}$, Amauri Alves de Alvarenga ${ }^{3}$, \\ Raírys Cravo Nogueira ${ }^{4}$, Eduardo Bucsan Emrich ${ }^{5}$, Cristiano Martinotto ${ }^{1}$
}

\begin{abstract}
RESUMO
A mangabeira, espécie nativa do Cerrado, destaca-se por possuir um grande potencial como planta frutífera e produtora de borracha. No entanto, suas sementes apresentam recalcitrância, dificultando sua propagação, o que torna evidente a necessidade da obtenção de mudas por via assexuada. Neste contexto, o cultivo in vitro apresenta-se como uma alternativa a ser utilizada. Com o presente trabalho, visou-se estabelecer uma metodologia de micropropagação da mangabeira via organogênese direta. Para a obtenção de brotações, segmentos caulinares com até duas gemas laterais foram inoculados em meio de cultura WPM, suplementado com diferentes concentrações de BAP $\left(0,0 ; 1,0 ; 2,0 ; 3,0 ; 4,0\right.$ e $\left.5,0 \mathrm{mg} \mathrm{L}^{-1}\right)$. Para o enraizamento, brotações foram inoculadas em meio WPM, suplementado com $0,1 \%$ de carvão ativado e diferentes concentrações de ANA $\left(0,0 ; 1,0 ; 2,0\right.$ e $\left.3,0 \mathrm{mg} \mathrm{L}^{-1}\right)$ ou AIB $\left(0,0 ; 1,0 ; 2,0 ; 3,0\right.$ e 4,0 $\left.\mathrm{mg} \mathrm{L}^{-1}\right)$. As brotações inoculadas permaneceram em sala de crescimento por 15 dias, quando foram transferidas para meio WPM sem reguladores de crescimento. As concentrações de 5,0 $\mathrm{mg} \mathrm{L}^{-1}$ e $3,0 \mathrm{mg} \mathrm{L}^{-1}$ de BAP foram as mais eficientes na indução, respectivamente, de brotações e gemas. O maior comprimento das brotações foi verificado em meio suplementado com $1,0 \mathrm{mg} \mathrm{L}^{-1}$ ou $2,0 \mathrm{mg} \mathrm{L}^{-1} \mathrm{de} \mathrm{BAP}$. A maior formação de calos ocorreu em meio suplementado com $4,0 \mathrm{mg} \mathrm{L}^{-1}$ dessa citocinina. A auxina ANA não se mostrou eficiente, nas concentrações testadas, no enraizamento in vitro de brotações de mangabeira. Na presença de $3,0 \mathrm{mg} \mathrm{L}^{-1} \mathrm{de}$ AIB, $20 \%$ das brotações enraizaram.
\end{abstract}

Termos para indexação: Micropropagação, brotações, enraizamento.

\begin{abstract}
The mangabeira presents potential for fruit and rubber production. Since the seeds are recalcitrant which makes difficult its propagation, new approaches are needed in order to obtain plants through asexual methods. In this context, the process of in vitro culture presents as an alternative for the mangabeira propagation. The objective of the present work was to establish a micropropagation methodology of mangabeira through direct organogenesis. To obtain shoots, nodal segments collected from in vitro germinated seedlings were inoculated in WPM medium supplemented with different concentrations of BAP $\left(0.0 ; 1.0 ; 2.0 ; 3.0 ; 4.0\right.$ e $\left.5.0 \mathrm{mg} \mathrm{L}^{-1}\right)$. For root induction, shoots were inoculated in WPM medium supplemented with $0.1 \%$ activated charcoal and different concentrations of NAA $\left(0.0 ; 1.0 ; 2.0 \mathrm{e} 3.0 \mathrm{mg} \mathrm{L}^{-1}\right)$ or IBA $\left(0.0 ; 1.0 ; 2.0 ; 3.0 \mathrm{e}^{2} .0 \mathrm{mg} \mathrm{L}^{-1}\right)$. The inoculated shoots were maintained in for 15 days a growth room after which were transferred to a free grow regulator WPM medium. The concentrations of $5.0 \mathrm{mg} \mathrm{L}^{-1}$ and $3.0 \mathrm{mg} \mathrm{L}^{-1} \mathrm{BAP}$ were the most eficient for shoots and buds induction, respectively. Higher shoot length was observed in medium suplemented with $1.0 \mathrm{mg} \mathrm{L}^{-1}$ or $2,0 \mathrm{mg} \mathrm{L}^{-1} \mathrm{BAP}$. The higher callus formation occurred in medium suplemented with $4.0 \mathrm{mg} \mathrm{L}^{-1}$ BAP. The use of NAA was not efficient, in all tested concentrations, to induce in vitro root formation in shoots. In presence of $3.0 \mathrm{mg} \mathrm{L}^{-1} \mathrm{IBA}, 20 \%$ of the shoots developed roots.
\end{abstract}

Index terms: Micropropagation, shooting, rooting.

(Recebido em 20 de outubro de 2005 e aprovado em 22 de maio de 2006)

\section{INTRODUÇÃO}

A mangabeira (Hancornia speciosa Gomes), espécie arbórea nativa do Cerrado, apresenta um grande potencial como planta frutífera e como produtora de borracha. No entanto, com a inexistência de plantios racionais e tecnificados, o extrativismo é, atualmente, sua única forma de exploração, constituindo-se, assim, numa grande barreira para o aproveitamento de todas as suas potencialidades.

O estabelecimento de plantios comerciais da mangabeira tem sido dificultado pelo curto período de armazenamento das sementes e pelo insucesso da sua propagação por estaquia.

\footnotetext{
'Engenheiro(a) Agrônomo(a) - Doutoranda(o) em Fisiologia Vegetal - Universidade Federal de Lavras/UFLA - Cx. P. 3037 - $37200-000$ - Lavras, MG fernandapsoares@hotmail.com; cmartinotto@yahoo.com.br

Engenheiro Agrônomo - Professor Associado, Setor de Fisiologia Vegetal - Departamento de Biologia/DBI -Universidade Federal de Lavras/UFLA Cx. P. 3037 - 37200-000 - Lavras, MG - renpaiva@ufla.br ${ }^{3}$ Engenheiro Agrônomo - Professor Titular, Setor de Fisiologia Vegetal - Departamento de Biologia/DBI - Universidade Federal de Lavras/UFLA - Cx. P. 3037 37200-000 - Lavras, MG - amauriaa@ufla.br

${ }^{4}$ Bióloga, Doutora em Fisiologia Vegetal - Universidade Federal de Lavras/UFLA - Cx. P. 3037 - 37200-000 - Lavras, MG - raírys@yahoo.com.br ${ }^{5}$ Graduando em Agronomia - Universidade Federal de Lavras/UFLA - Cx. P. 3037 - 37200-000 - Lavras, MG - bucsan_emrich@yahoo.com.br
} 
Avanços na instalação de pomares comerciais implicam na necessidade de produção de mudas de alta qualidade e baixo custo, o que requer o uso de métodos intensivos de propagação (Corrêa, 1990; Yui, 1990), sendo a propagação vegetativa essencial para a manutenção dos caracteres agronômicos desejáveis do genótipo.

O desenvolvimento de técnicas de cultura de tecidos vegetais tem sido uma das contribuições mais significativas para o avanço do processo de propagação. A micropropagação é a técnica alternativa mais utilizada, com a finalidade de obtenção de um grande número de plantas uniformes, independente da época do ano (Borthakur et al., 1999). Pode ser realizada por organogênese ou embriogênese somática. Na organogênese ocorre a diferenciação de brotações e raízes durante o desenvolvimento vegetal. A embriogênese somática envolve o desenvolvimento de embriões a partir de células somáticas embriologicamente competentes in vitro (Ahuja, 1992). Segundo Bonga (1985), por ser de manipulação relativamente fácil, principalmente devido ao tamanho do explante utilizado, e por originar plantas em geral geneticamente mais estáveis, a proliferação de gemas axilares é a técnica mais utilizada para a micropropagação de plantas lenhosas, como a mangabeira.

De acordo com Sano \& Almeida (1998), observamse diversos padrões de multiplicação, de acordo com a espécie cultivada. Existem espécies que, na mesma subcultura, produzem até cem brotos por explante. Para as plantas do Cerrado, os poucos trabalhos já realizados indicam que a produção de brotos na mesma subcultura é da ordem de dez por explante. Entretanto, observa-se que quanto maior o número de brotos, menor será o seu comprimento. Além disso, muitas vezes, os brotos apresentam características morfológicas anormais. A vantagem de se obter brotos normais e alongados (maiores do que $1,5 \mathrm{~cm}$ ) é que esses enraizam mais facilmente do que brotos curtos.

$\mathrm{O}$ crescimento e a organogênese in vitro são altamente dependentes da interação entre as substâncias de crescimento que ocorrem naturalmente na planta (hormônios) e os análogos sintéticos (reguladores de crescimento), os quais são adicionados ao meio de cultura (George, 1996).

As auxinas são substâncias que controlam o crescimento e o alongamento celular e as citocininas estimulam a divisão celular e reduzem a dominância apical. O balanço entre estes dois tipos de reguladores controla muitos aspectos da diferenciação celular e organogênese nas culturas de tecidos e orgãos (Pasqual, 2001).
Segundo Grattapaglia \& Machado (1998), das citocininas comercialmente disponíveis, a 6benzilaminopurina (BAP), é a que, em geral, apresenta melhores resultados in vitro para promover a multiplicação de diversas espécies, sendo utilizada em aproximadamente $60 \%$ dos meios de cultivo, seguida da cinetina (KIN), com cerca de $23 \%$.

Quanto ao enraizamento, as auxinas mais utilizadas são o ácido indolbutírico (AIB) e o ácido naftalenoacético (ANA) (Assis \& Teixeira, 1998). As respostas às auxinas, no entanto, não são universais. Certas espécies, principalmente as lenhosas, enraízam com dificuldade ou não enraízam, mesmo na presença de auxinas e algumas espécies até dispensam o uso de reguladores de crescimento no seu enraizamento (Rohr \& Hanus, 1987).

O objetivo deste trabalho foi estabelecer uma metodologia de micropropagação da mangabeira via organogênese direta a partir de segmentos caulinares, visando a produção de mudas dessa espécie para a implantação de pomares comerciais.

\section{MATERIAL E MÉTODOS}

\section{Indução in vitro de brotações}

Plântulas de mangabeira obtidas da germinação de sementes in vitro em meio WPM suplementado com 0,2 $\mathrm{mg} \mathrm{L}^{-1}$ de $\mathrm{GA}_{3}$ e $15 \mathrm{~g} \mathrm{~L}^{-1}$ de sacarose, com 60 dias de idade, foram utilizadas como fonte de explantes para este experimento.

Segmentos caulinares com o ápice excisado, contendo um nó e duas gemas axilares foram inoculados em meio de cultura WPM (Lloyd \& McCown, 1980), suplementado com diferentes concentrações de BAP $\left(0,0 ; 1,0 ; 2,0 ; 3,0 ; 4,0\right.$ e $\left.5,0 \mathrm{mg} \mathrm{L}^{-1}\right)$ e $3 \%$ de sacarose. O meio foi solidificado com $0,7 \%$ de ágar e seu $\mathrm{pH}$ ajustado para 5,8 antes da autoclavagem a $120^{\circ} \mathrm{C}$, durante 20 minutos.

Após a inoculação, os segmentos foram mantidos em sala de crescimento a $25 \pm 2^{\circ} \mathrm{C}$ de temperatura, irradiância de $36 \mathrm{mmol} \mathrm{m}^{-2} \mathrm{~s}^{-1}$ e fotoperíodo de 16 horas. Foram avaliados o número de brotações e gemas axilares por explante inoculado, o comprimento da maior brotação e a presença de calos na base dos explantes, aos 30 dias de cultivo.

O delineamento utilizado foi o inteiramente casualizado com vinte repetições por tratamento, sendo cada repetição composta por um tubo de ensaio contendo um explante.

Com relação ao número de brotações e gemas produzidas, ajustaram-se modelos log-lineares, cujas 
equações descrevem a resposta média de cada variável analisada. Já em relação à presença de calos na base dos explantes, devido a variável de interesse ser dicotômica, apresentando dois possíveis resultados (SIM/NÃO), justificou-se o ajuste de um modelo de regressão logística. A qualidade destes modelos foi estimada via teste quiquadrado de Person e análise de Deviance (Balakrishnan, 1992), respectivamente.

\section{Enraizamento in vitro de brotações}

Brotações obtidas in vitro, no experimento anterior, foram inoculadas em meio de cultura WPM contendo diferentes concentrações de ANA $\left(0,0 ; 1,0 ; 2,0\right.$ e 3,0 $\left.\mathrm{mg} \mathrm{L}^{-1}\right)$ ou AIB $\left(0,0 ; 1,0 ; 2,0 ; 3,0\right.$ e 4,0 $\left.\mathrm{mg} \mathrm{L}^{-1}\right), 3 \%$ de sacarose e $0,1 \%$ de carvão ativado. O meio foi solidificado com $0,7 \%$ de ágar e seu pH ajustado para 5,8 antes da autoclavagem a $120^{\circ} \mathrm{C}$, durante 20 minutos.

Após a inoculação, as brotações foram mantidas em sala de crescimento a $25 \pm 2^{\circ} \mathrm{C}$ de temperatura e na ausência de luz, por 15 dias. Decorrido esse período, foram transferidos para meio de cultura WPM sem reguladores de crescimento e na ausência de carvão ativado. Trinta dias depois, a formação de raízes nos diferentes tratamentos foi avaliada.

O delineamento utilizado foi o inteiramente casualizado com vinte repetições por tratamento, sendo cada repetição composta por um tubo de ensaio, contendo uma brotação.

\section{RESULTADOS E DISCUSSÃO}

\section{Indução in vitro de brotações}

Os modelos utilizados para a análise estatística do número de brotos e de gemas por explante, respectivamente (1) e (2), mostraram-se adequados aos dados experimentais, já que as probabilidades do teste qui-quadrado de Person, respectivamente 0,996 e 0,704 , foram superiores ao nível de significância, preestabelecido em 5\%.

$$
\begin{gathered}
\bar{y}_{\text {brotos }}=e^{0,2636+0,4127 \mathrm{BAP}-0,0355 \mathrm{BAP}^{2}} \\
\overline{\mathrm{y}}_{\text {gemas }}=e^{0,8924+0,6772 \mathrm{BAP}-0,0982 \mathrm{BAP}^{2}}
\end{gathered}
$$

Houve formação de brotações em todos os tratamentos testados (Figura 1), mesmo na ausência do regulador de crescimento. Entretanto, a adição de BAP ao meio de cultura proporcionou aumento do número de novos brotos formados por explante.

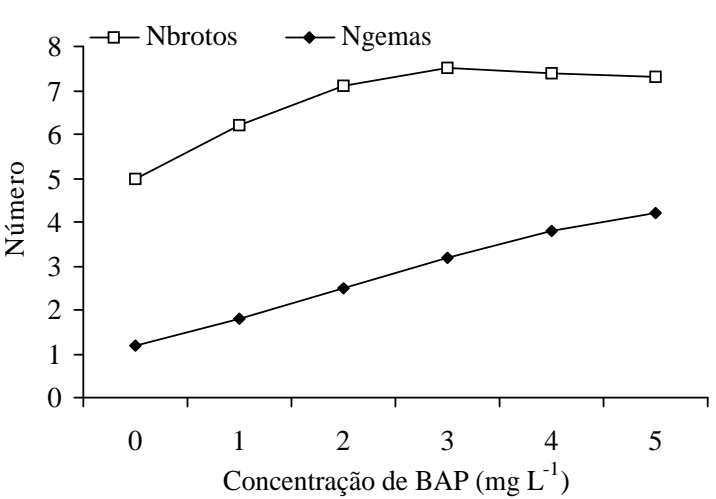

FIGURA 1 -Número médio de brotos e gemas nos explantes caulinares de mangabeira para cada concentração de BAP acrescentada ao meio de cultura WPM. UFLA, Lavras, 2005.

De acordo com Preece (1995), as citocininas têm função primordial na divisão celular e atuam também na quebra da dominância apical e na indução e crescimento de brotações. Grattapaglia e Machado (1998) afirmam que o tipo de citocinina e a sua concentração são os fatores que mais influenciam o sucesso da multiplicação in vitro.

Um efeito sinergístico do BAP sobre o número total de brotos formados foi verificado. Para esta variável, a maior média observada foi de quatro brotações, para explantes cultivados na concentração de $5,0 \mathrm{mg} \mathrm{L}^{-1}$ de BAP. Para Nogueira (2003), ao contrário, concentrações acima de 4,0 $\mathrm{mg} \mathrm{L}^{-1}$ dessa citocinina não foram eficientes na indução de brotos axilares em segmentos nodais de murici-pequeno (Byrsonima intermedia A. Juss.).

Quanto ao número de gemas laterais, um aumento foi verificado até a concentração de $3,0 \mathrm{mg} \mathrm{L}^{-1}$ de BAP (7,5 gemas por explante). A partir deste ponto, ocorreu um decréscimo.

Pasqual \& Barros (1992) relataram que o melhor resultado para a proliferação de gemas em segmentos nodais de barbatimão (Stryphnodendron adstringens Mart.) foi dado pela concentração de $4,0 \mathrm{mg} \mathrm{L}^{-1}$ de BAP. Santos (2004), por outro lado, ao induzir brotações em segmentos nodais de pequizeiro (Caryocar brasiliense Camb.), verificou um decréscimo do número de gemas a partir da concentração de $1,0 \mathrm{mg} \mathrm{L}^{-1}$ de BAP.

$\mathrm{O}$ efeito das diferentes concentrações de BAP sobre o tamanho da maior brotação formada foi significativo.

O maior comprimento médio das brotações, 3,175 ; 3,0 e 2,875 cm, foi verificado nos tratamentos com 1,0; 2,0 e 3,0 $\mathrm{mg} \mathrm{L}^{-1}$ de BAP, respectivamente (Tabela 1). Acima dessas concentrações houve uma tendência de redução do tamanho dos brotos formados. 
TABELA 1 - Teste de Tukey para comparação das médias referentes ao comprimento das brotações nas diferentes concentrações de BAP adicionadas ao meio WPM. UFLA, Lavras, 2005.

\begin{tabular}{ccc}
\hline $\begin{array}{c}\text { Concentrações de } \\
\text { BAP }\left(\mathbf{m g ~ L}^{\mathbf{1}}\right)\end{array}$ & Médias & \\
\hline 1,0 & 3,175 & $\mathrm{a}$ \\
2,0 & 3,000 & $\mathrm{a}$ \\
3,0 & 2,825 & $\mathrm{ab}$ \\
5,0 & 2,575 & $\mathrm{~b}$ \\
4,0 & 2,525 & $\mathrm{~b}$ \\
0,0 & 1,850 & $\mathrm{c}$ \\
\hline
\end{tabular}

Médias seguidas de mesma letra não diferem entre si pelo teste de Tukey $(\mathrm{p}<0,05)$.

Resultados semelhantes foram encontrados por Chitra \& Padmaja (1999) ao induzirem brotações em ápices caulinares de amora (Morus indica L. cultivar M-5). Tabachnik \& Kester (1977) observaram que concentrações de BAP acima de 1,0 $\mathrm{mg} \mathrm{L}^{-1}$ inibiram o alongamento de brotações de pessegueiro e amendoeira.

De acordo com Yui et al. (1990), a utilização de concentrações elevadas de BAP promove a formação de grande número de brotos em detrimento, porém, de seu desenvolvimento. Trabalhando com sucupira-preta (Bowdichia virgilioides Kunth), Silveira et al. (1996) observaram que segmentos caulinares dessa espécie, quando inoculados em meio de cultura suplementado com 4,0 mg L-1 de BAP, produziam, em média, 10 brotos de $10 \mathrm{~mm}$ de comprimento, enquanto que em 1,0 $\mathrm{mg} \mathrm{L}^{-1}$ de BAP, o mesmo tipo de explante produzia quatro brotos de $23 \mathrm{~mm}$ de comprimento cada um.

Grattapaglia \& Machado (1998) relatam que a tendência de diminuição do comprimento de brotações a partir de determinada concentração pode decorrer de um possível efeito fitotóxico da citocinina. Para Narayanaswamy (1977), a toxidez causada pelo excesso de reguladores de crescimento no meio de cultura, ou pelo prolongado período de tempo em que a cultura permanece exposta a eles, pode provocar alterações genéticas, fisiológicas e morfológicas, resultando na redução da taxa de multiplicação e no encurtamento dos caules, o que dificulta a individualização das plantas e o processo de enraizamento.

O modelo utilizado para a análise estatística da ocorrência de calos na base dos explantes caulinares de mangabeira é dado pela equação abaixo (3).

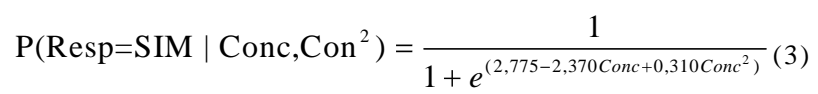

Por meio da probabilidade da Deviance $(\mathrm{p}=0,255)$, verifica-se a adequacidade do modelo, tendo em vista o nível de significância, fixado em $5 \%$.

Na Figura 2, observa-se a não expressividade da calogênese na ausência do regulador de crescimento.

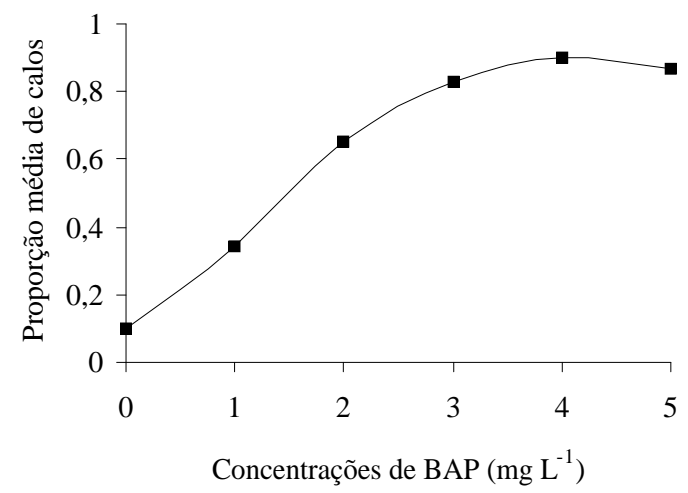

FIGURA 2 - Proporção média de calos na base dos explantes para cada concentração de BAP acrescentada ao meio de cultura WPM. UFLA, Lavras, 2005.

A ocorrência de calos na base dos explantes aumentou com o acréscimo de BAP ao meio de cultura, até a concentração de 4,0 $\mathrm{mg} \mathrm{L}^{-1}(90 \%)$. A partir deste ponto, uma tendência de queda dessa variável resposta foi verificada. Resultados semelhantes foram obtidos por Fráguas et al. (2004) que, trabalhando com a figueira 'Roxo de Valinhos', encontraram maior peso da matéria fresca $(1,672 \mathrm{~g})$ e seca $(0,85 \mathrm{~g})$ de calos basais de explantes caulinares, utilizando o meio de cultura WPM, suplementado com 4,0 $\mathrm{mg} \mathrm{L}^{-1}$ de BAP.

Em pesquisa com Inga vera subsp. affinis, Soares (2003) observou que, à medida que se aumentou a concentração de BAP, estimulou-se a formação de calos em segmentos caulinares. As concentrações de 6,0, 9,0 e 12,0 mg $\mathrm{L}^{-1}$ deste regulador foram as que apresentaram os resultados mais significativos, entre $70 \%$ e $80 \%$ de formação de calos.

\section{Enraizamento in vitro de brotações}

As doses de ANA utilizadas nesse experimento não proporcionaram a formação de raízes nas brotações de mangabeira cultivadas in vitro. Este regulador não exerceu efeito positivo na rizogênese e os níveis internos de auxinas dos explantes não foram suficientes para desencadear este processo morfogenético. Segundo Kulescha (1988), o nível das auxinas endógenas é o que determina a formação de raízes adventícias, ou seja, é o acúmulo de auxinas endógenas que induz à formação de raízes. 
A testemunha (ausência de ANA no meio de cultura) também não promoveu o enraizamento. É possível que o explante tenha apresentado concentrações endógenas de citocininas ou residuais dos experimentos de multiplicação, que podem ter desfavorecido o balanço hormonal para a emergência de raízes. A rizogênese é geralmente inibida por altas concentrações de citocinina que, utilizada na indução de brotações, pode afetar negativamente o alongamento dos primórdios radiculares (Pasqual, 1998).

Em meio de cultura suplementado com $3,0 \mathrm{mg} \mathrm{L}^{-1}$ de AIB, foi observado o enraizamento de $20 \%$ das brotações de mangabeira inoculadas. Nenhuma freqüência de enraizamento foi verificada nas demais concentrações dessa auxina.

Segundo Wang \& Anderson (1988), o AIB é a auxina sintética mais comumente utilizada na indução de enraizamento. Por apresentar a propriedade de promover a formação de primórdios radiculares, este regulador tem sido utilizado para induzir o enraizamento de numerosas espécies vegetais

Efeito favorável do AIB no processo de rizogênese foi obtido por Bonilla (2002) em estudos com tangará-açu (Rudgea viburnoides).

Deccetti (2000), embora utilizando diferentes concentrações de AIB no meio de cultura, concluiu que o melhor enraizamento de segmentos nodais de Annona glabra é obtido na ausência deste regulador, em plantas cultivadas na presença de luz. Para Nogueira (2003), trabalhando com murici-pequeno (Byrsonima intermedia A. Juss), o AIB não se mostrou eficiente na indução de raízes.

Segundo Pasqual (1998), diferenças genotípicas na resposta à auxina podem ser causadas pela habilidade diferenciada do tecido em absorver e ou metabolizar a auxina sintética, convertendo-a para auxina endógena (AIA).

\section{CONCLUSÕES}

A utilização de BAP promove resposta eficiente na indução de multibrotações em segmentos nodais de mangabeira.

As concentrações de $1,0 \mathrm{mg} \mathrm{L}^{-1}$ ou $2,0 \mathrm{mg} \mathrm{L}^{-1} \mathrm{de}$ BAP possibilitam a obtenção de brotações mais desenvolvidas, embora induzam também a formação de calos na base dos explantes.

O ANA não induz, nas concentrações testadas, a formação de raízes em brotações de mangabeira.

O AIB induz, somente na concentração de $3,0 \mathrm{mg} \mathrm{L}^{-1}$, a formação de raízes em brotações de mangabeira.

\section{REFERÊNCIAS BIBLIOGRÁFICAS}

AHUJA, M. R. Micropropagation of woody plants. London: Kluwer Academic Publishers, 1992. v. 41, 507 p.

ASSIS, T. F.; TEIXEIRA, S. L. Enraizamento de plantas lenhosas. In: TORRES, A. C.; CALDAS, L. S.; BUSO, J. A. Cultura de tecidos e transformação genética de plantas. Brasília: EMBRAPA-SPI/EMBRAPA-CNPH, 1998. v. 1, p. 261-296.

BALAKRISHANAN, N. Handbook of the logidtic distribution. Statistics: Textbooks and monographs, New York, 1992. 602 p.

BONGA, J.M. Tissue culture techniques. In: BONGA, J.M., DURZAN, D.J. Tissue culture in forestry. Dordrecht: Martinus Nijhoff, 1985. p.4-35.

BONILLA, M.G.O. Propagação in vivo, indução, curva de crescimento de calos e abordagem fitoquímica em Rudgea viburnoides (CHAM) Benth. 2002. 162p. Tese (Doutorado em Fitotecnia) - Universidade Federal de Lavras, Lavras, MG.

BORTHAKUR, M.; HAZARIKA, J.; SINGH, R. S. A protocol for micropropagation of Alpinia galanga. Plant Cell, Tissue and Organ Culture, Amsterdam, v. 55, n. 3, p. 231-233, 1998.

CHITRA, D. S. V.; PADMAJA, G. Clonal propagation of mulberry (Morus indica L. cultivar M-5) thorooung in vitro culturae of nodal explants. Scientia Horticulturae, Amsterdam, v. 80, n. 3/4, p. 289-298, Apr. 1999.

CORREAA, D. de M. Enraizamento in vitro de portaenxertos de macieira (Malus domestica Borkh.). 1990. 50 p. Dissertação (Mestrado em Fitotecnia) - Escola Superior de Agricultura de Lavras, Lavras, MG.

DECCETTI, S. F. C. Propagação in vitro de Annona glabra L. 2000. 101 p. Dissertação (Mestrado em Fisiologia Vegetal) - Universidade Federal de Lavras, Lavras, MG.

FRÁGUAS, C.B., PASQUAL, M., PEREIRA, A.R. Multiplicação in vitro de Ficus carica L.: efeito da cinetina e do ácido giberélico. Ciência e Agrotecnologia, v.28, p.49$55,2004$.

GEORGE, E. F. Plant propagation by tissue culture. Part 1 The technology. Edington: Exegetics, 1996. 1574 p. 
GRATTAPAGLIA, D.; MACHADO, M. A. Micropropagação. In: TORRES, A. C.; CALDAS, L. S.; BUSO, J. A. Cultura de tecidos e transformação genética de plantas. Brasília: EMBRAPA-SPI/EMBRAPA-CNPH, 1998. v. 1, p. 183-260.

KULESCHA, Z. Recherches sur l'élaboration de substances de croissance of micropropagation. Acta Horticulturae, Wageningen, n. 230, p. 63-71, 1988.

LLOYD, G.; MCCOWN, B. Commercially-feasible micropropagation of Mountain laurel, Kalmia latifolia, by use of shoot tip culture. International Plant Propagation Society Proceedings, Washington, v. 30, p. 421-427, 1980.

NARAYANASWAMY, S. Regeneration of plants from tissue cultures. In: REINERT, J.; BAJAJ, Y. P. S. Applied and fundamental aspects of plant cell tissue and organ cuture. Berlin: Springer Verlag, 1977. p. 179-248.

NOGUEIRA, R. C. Propagação in vitro, análises anatômicas e bioquímicas de murici-pequeno (Byrsonima intermedia A. Juss.). 2003. 88 p. Dissertação (Mestrado em Fisiologia Vegetal) - Universidade Federal de Lavras, Lavras, MG.

PASQUAL, M.; BARROS, I. de. Efeito do ácido naftaleno acético e da 6-benzilaminopurina sobre a proliferação de brotos in vitro em barbatimão (Stryphnodendron adstringens (Mart.) Coville). Pesquisa Agropecuária Brasileira, Brasília, v. 27, n. 7, p. 1017-1019, jul. 1992.

PASQUAL, M.; RAMOS, J. D.; HOFFMANN, A.; CARVAlHO, G. R. Cultura de Tecidos Vegetais: Tecnologias e aplicações: meios de cultura. Lavras: FAEPE/ UFLA, 1998. $116 \mathrm{p}$.

PASQUAL, M. Textos acadêmicos: meios de cultura. Lavras: FAEPE/UFLA, 2001. 127 p.
PREECE, J. E. Can nutrient salts partially substitute for plant growth regulator? Plant Tissue Culture and Biotechnology, Oxford, n. 1, v. 1, p. 26-37, 1995.

ROHR, R.; HANUS, D. Vegetative propagation of wavy grain sycamore maple. Canadian Journal of Foresty Research, Ottawa, v. 17, n. 5, p. 418-420, May 1987.

SANO, S. M.; ALMEIDA, S. P. (Ed.) Cerrado: ambiente e flora. Planaltina: EMBRAPA-CPAC, 1998. 556 p.

SANTOS, B. R. Micropropagação de pequizeiro (Caryocar brasiliense Camb.). 2004. 239 p. Tese (Doutorado em Fisiologia Vegetal) - Universidade Federal de Lavras, Lavras, MG.

SILVEIRA, C. E.; CALDAS, L. S.; AMARAL, L. I. V. Efeito de 6-benzilaminopurina na proliferação in vitro de brotos de Bowdichia virgilioides Kunth (sucupira-preta). In: CONGRESSO NACIONAL DE BOTÂNICA, 47., 1996, Nova Friburgo. Resumos... Nova Friburgo: Sociedade Botânica do Brasil, 1996. p. 436.

SOARES, G. de A. Aspectos do cultivo in vitro do ingazeiro [Inga vera Willd. subsp.affinis (DC) T. D. Penn]. 2003. 90 p. Dissertação (Mestrado em Fisiologia Vegetal) Universidade Federal de Lavras, Lavras, MG.

WANG, Q.; ANDERSON, A. S. Propagation of Hibiscus rosa-sinensis: relations between stock plant, age, environment and growth regulator treatments. Acta horticulture, Wageningen, n. 227, p. 167-169, 1988.

YUI, E. Multiplicação in vitro de porta-enxertos de macieira (Malus domestica Borkh.). 1990. 69 p. Dissertação (Mestrado em Fitotecnia) - Escola Superior de Agricultura de Lavras, Lavras, MG. 